\title{
Garimpando memórias: entrevista com Jorge Pinto Ribeiro (1955-2012)
}

Rev Bras Ativ Fis Saúde p. 495-499 DOI: http://dx.doi.org/10.12820/23171634.2012v17n6p495

1 Escola Superior de Educação Física, Departamento de Desportos, Universidade Federal do Rio Grande do Sul, Porto Alegre, RS, Brasil.

Christiane Garcia Macedo

Leila Carneiro Mattos ${ }^{1}$

Carla Ferreira ${ }^{1}$

No dia 18 de junho de 2012 Jorge Pinto Ribeiro concedeu uma entrevista ${ }^{1}$ ao projeto Garimpando Memórias, desenvolvido pela equipe do Centro de Memória do Esporte da Escola de Educação Física da Universidade Federal do Rio Grande do $\mathrm{Sul}^{2}$. O encontro aconteceu no Hospital de Clínicas de Porto Alegre e durante aproximadamente 40 minutos o professor relatou sua trajetória acadêmica, sua aproximação com a Escola de Educação Física da UFRGS e sua relação com a pesquisa tendo como eixo condutor um roteiro por nós elaborado. Depois de finalizadas todas as etapas de processamento, considerando o aporte teórico-metodológico da História Oral, a entrevista foi devolvida ao professor Jorge que assinou uma carta autorizando a sua divulgação na íntegra ou em partes ${ }^{3}$.

Considerando a relevância de sua atuação no campo da pesquisa, da prática médica e da formação de profissionais no cenário nacional e internacional, entendemos que a divulgação daquilo que narrou sobre si mesmo contribui não apenas para conhecer sua trajetória pessoal mas, sobretudo, para entender o desenvolvimento da pesquisa científica em Medicina do Esporte, área na qual foi um dos pioneiros no Brasil.

\section{A ENTREVISTA}

Christiane Macedo - Professor, gostaríamos que o senhor falasse sobre sua relação acadêmica com a $\mathrm{ESEF}^{4}$, quando iniciou e como foi essa aproximação?

Jorge Pinto Ribeiro - Eu comecei a trabalhar ainda como aluno de terceiro ano na Faculdade de Medicina em 1975. Fui convidado a iniciar... Na realidade fui indicado pelo professor Jayme Werner dos Reis para começar uma atividade como estagiário no Laboratório de Pesquisa do Exercício ${ }^{5}$, sob orientação do professor Eduardo Henrique de Rose. Naquela época o LAPEX já existia, já tinha sido equipado e eu comecei a trabalhar imediatamente após um grande Congresso Internacional de Medicina do Esporte que o professor De Rose organizou em Porto Alegre. Foi assim que começou a indicação: pelo professor de natação, Jayme Werner dos Reis, e à convite do professor De Rose. Essa indicação do professor

\footnotetext{
1 A entrevista foi realizada respeitando as seguintes etapas de processamento: Realização e registro em gravador digital: Christiane Garcia Macedo, Carla Ferreira e Leila Carneiro Mattos; Transcrição: Carina Kaiser Miranda da Silva e Leila Carneiro Mattos; Copidesque e Pesquisa: Silvana Vilodre Goellner 2 Maiores informações em http://www.ufrgs.br/ceme

3 A entrevista tem 9 páginas. Suprimimos os trechos que se referem majoritariamente à Escola de Educação Fisica da UFRGS por considerar que foge do escopo da revista. Sua transcrição na íntegra pode ser acessada no seguinte endereço: http://www.lume.ufrgs.br/handle/10183/56135 4 Escola de Educação Física da Universidade Federal do Rio Grande do Sul.

5 O Laboratório de Pesquisa do Exercício (LAPEX) foi criado na Escola de Educação Física em 1973.
} 
Peixinho ${ }^{6}$ veio porque ele foi meu professor de Educação Física na época que eu estudava no Colégio de Aplicação 7 . Sendo médico e o LAPEX sendo uma área exatamente multiprofissional havia naquele momento uma geração de alunos de Educação Física e também de alunos de Medicina que começavam a trabalhar naquele meio.

C.M. - E como estudante teve mais alguma atividade que você fez na ESEF com o Diretório, prática esportiva, cursos?

J.R. - Não! Na realidade eu nunca cursei a Faculdade porque eu fazia a Faculdade de Medicina. Eu entrei no LAPEX e naquela época nenhuma das pessoas, inclusive aquelas pessoas mais sênior, como era o caso do professor De Rose, nenhuma das pessoas tinha formação acadêmica. $\mathrm{O}$ professor De Rose tinha ampla experiência como médico do esporte e era professor também na $\mathrm{PUC}^{8}$ naquela época, mas nenhum tinha formação acadêmica. Mas já naquela época, o grupo do professor De Rose particularmente, tinha um contato internacional muito extenso, então, ele já havia enviado alguns dos estudantes para fazer estágios em laboratórios internacionais e naquele momento ele me deu uma incumbência que era de montar uma técnica que, naquela época, era muito importante que era de biópsia muscular e esta foi a minha primeira atividade no LAPEX. Eu realmente fiz isso, estudei toda a técnica, acabamos publicando um trabalho especificamente naquela época; um trabalho nacional e foi, na realidade, a primeira vez que no Brasil se fez biópsia muscular. Tanto na área de Medicina do Esporte como também na área de Neurologia eu fui o primeiro a montar o que se chama de histoquímica muscular para a diferenciação de tipos de fibras. Então isso se estendeu porque, na realidade, eu comecei a trabalhar no fim de 1975 e se estendeu ao longo do ano de 1976 e no início de 1977 eu recebi uma bolsa. Naquela época as nossas bolsas de iniciação científica eram pagam não pela universidade nem pelo $\mathrm{CNPq}^{9}$; eram pagas por uma verba especial da Federação Brasileira de Medicina do Esporte e existiam essas bolsas de curta estadia no exterior. Eu recebi uma dessas bolsas assim como vários outros colegas também receberam [...] eu tive a oportunidade de estagiar em Roma que era o Comitê Olímpico Italiano, um ambiente fantástico de avaliação de atletas, com o professor Antonio Dal Monte; depois em Colônia que também tinha uma avaliação de atletas fabulosa na Alemanha. Depois eu fui para Estocolmo onde estagiei no Instituto Karolinska e, finalmente, em Jyväskylä na Finlândia. Então foram quatro estágios curtos, para me expor a várias formas de avaliação de atletas e de pesquisa. Eu diria que esses estágios se pode dividir em duas experiências distintas: a primeira experiência tinha avaliação de atletas, que seria em Roma e em Colônia, e a segunda experiência de pesquisa profunda em Fisiologia do Exercício.

Nos anos 1970 a Escandinávia dominava a pesquisa mundial em Fisiologia do Exercício, e para minha grande satisfação, quando eu cheguei em Estocolmo e depois em Jyväskylä eu me dei conta que eu naquela época tinha sido aluno de Medicina, tinha sido capaz de estudar tudo que existia sobre o tema que me interessava que era tipos de fibras musculares e desempenho físico. Lembrando que

6 Apelido conferido à Jayme Werner dos Reis.

7 Vinculado à Universidade Federal do Rio Grande do Sul.

8 Pontifícia Universidade Católica.

9 Conselho Nacional de Desenvolvimento Científico e Tecnológico. 
naquela época não tinha computador, cada referência bibliográfica que eu tivesse que ler, eu diria que 70\% delas existiam na nossa biblioteca; nós tínhamos e temos ainda uma biblioteca maravilhosa no Departamento de Fisiologia, mas 30\% nós tínhamos que mandar vir do exterior para estudar. Mas eu cheguei lá conhecendo toda literatura e isso foi uma experiência vital para me dar conta que eu era capaz de aprender sozinho e chegar junto às maiores autoridades do mundo e sendo um aluno de Medicina. Levar referências que eles não conheciam. Então esse foi um momento muito importante, essas alturas eu estou entrando no quinto ano da Faculdade de Medicina e eu voltei para Porto Alegre depois deste estágio e lá eu me dei conta de uma outra coisa: que o que eu estava montando era desenvolvido demais para o resto que estava sendo feito no LAPEX porque técnicas mais fundamentais ainda não tinham sido montadas no LAPEX. E ai eu montei duas outras técnicas: a medida de consumo de oxigênio, usando análise sequencial e analisadores químicos, isso também acabei publicando um trabalho, ainda nacional; e depois nós recebemos um equipamento maravilhoso de ergoespirométrica que era o melhor da época no mundo, também desenvolvi as técnicas nessa área. Então eu diria que 1977 foi o ano de complementar aquilo que eu tinha feito na área muscular para a área cardiorrespiratória, e começamos a trabalhar em algo que, na realidade, até hoje eu continuo produzindo nisso que é uma das minhas linhas de pesquisa chamada limiares ventilatórios e metabólicos durante o exercício. E publiquei o primeiro trabalho no país sobre o que naquela época se chamava de limiar anaeróbico. Essa foi, eu diria, o resumo da minha iniciação científica no LAPEX, sempre com um estímulo fantástico do professor De Rose, uma oportunidade imensa porque ele tinha contatos internacionais, nós tínhamos dentro da ESEF um centro bibliotecário que tinham os melhores livros do mundo na área, não faltava livro aqui. A nossa bibliotecária era muito competente, tudo isso com essa verba da Federação, então, material para estudar nós tínhamos, equipamentos de alta qualidade nós tínhamos, faltava realmente eram os pesquisadores que nós ainda não éramos, nós estávamos em iniciação científica.

Eu me formei na faculdade, comecei a residência médica em Medicina Interna mas continuei trabalhando do LAPEX. Nós tínhamos também por causa do grande prestígio internacional do professor De Rose, anualmente, nós recebíamos médicos que vinham de outros países - no início América Latina - depois muitos espanhóis vinham também para fazer formação no LAPEX. No início era um médico por ano, no início dos anos 1980 nós tínhamos quinze médicos. E no final eu terminava a minha atividade aqui na residência, agora já médico e eu supervisionava o trabalho desses médicos na avaliação funcional de atletas lá no LAPEX. Tudo isso para mim teve um resultado muito importante porque muito precocemente eu, mesmo sem uma orientação de um pesquisador formado, tive a oportunidade de buscar o conhecimento. E naquela época como Medicina do Esporte era uma ciência muito subdesenvolvida ainda, mesmo nós que éramos alunos de Medicina dávamos palestras em congressos brasileiros, porque os médicos mais velhos não estudavam como nós. Então já muito cedo eu comecei a dar palestras, o professor De Rose também me dava a oportunidade de ajudá-lo na disciplina de graduação que ele tinha na Faculdade de Medicina da PUC. E isso foi uma oportunidade fantástica para eu iniciar não só como pesquisador mas também como professor pois ainda como aluno eu funcionava como auxiliar da disciplina e tudo isso foi experiência acumulada.

Bom, foram de 1975 até 1978 iniciação científica, depois 1979, 1980 e 1981 era residente aqui, e em 1980 surgiu a oportunidade de eu ser contratado como pro- 
fessor na ESEF. Fui contratado, e como não existia ainda a disciplina de Fisiologia do Exercício, eu fui trabalhando no LAPEX e lá continuei fazendo esse trabalho de supervisão dos médicos e dos professores que faziam avaliação de atletas. Até que em 1985 de novo, pelo estímulo do professor De Rose que tinha uma visão muito clara de que o nosso grupo tinha que se diferenciar para termos a capacidade de nos tornarmos pesquisadores internacionais... Como não tinha experiência em pesquisa, em Medicina do Esporte no Brasil, existiam alguns poucos grupos que faziam uma Fisiologia do Exercício muito tênue, muito pouco exercício e muita Fisiologia, por exemplo, na Escola Paulista de Medicina. O entendimento do professor De Rose era que nós tínhamos que ir para fora. E isso ele fez. Ele foi para a Alemanha, para Colônia fazer doutorado, eu fui para Boston. [...]

O que eu fiz de importante em todos esses anos eu formei agora já 29 mestres e 25 doutores, já mandei mais de 20 pessoas para o exterior seguindo exatamente o modelo que o professor De Rose propôs naquela época sem ele ser pesquisador, mas ele sabia dessas coisas. Então, fomos todos para o exterior, este foi um período em que de 1981 à 1985, é um período que o LAPEX esvaziou porque muita gente saiu ao mesmo tempo. Então o professor Belmar ${ }^{10}$ ficou coordenando o LAPEX mas com pouca gente para trabalhar. Foi uma época que o LAPEX diminuiu suas atividades mas manteve algo de muito importante que é o fluxo de avaliação. Nós tivemos sempre duas linhas: a avaliação de atletas e a avaliação de sedentários que iniciavam programas de exercício. Foi algo que o professor De Rose começou lá no início dos anos 1970 e o professor Belmar continuou nesta parte, principalmente da avaliação de sedentários, que era a área de que ele atuava mais. A avaliação de atletas diminuiu, em 1985 eu voltei [...] e reestruturamos o LAPEX e ai já em outro cenário. Já em um cenário com pessoas com formação acadêmica completa: eu fiz meu doutorado e a minha cardiologia, doutorado na Boston University e a Cardiologia na Harvard e eu voltei com uma produção muito forte, uma produção no sentido de publicações internacionais. E antes de voltar em 1984 nós publicamos o primeiro trabalho feito integralmente aqui e publicado no exterior, que foi a dissertação de mestrado do professor Arno Black, que tinha feito sua dissertação. Eu orientei à distância depois escrevemos o trabalho e foi publicado no European Journal of Applied Physiology, então, este é o primeiro trabalho em revista indexada publicado na história da ESEF. E ali para adiante eu voltei a produzir aqui. [...]. No final dos anos 1980 o curso de pós-graduação de Medicina do Esporte atingiu um número muito elevado, nós naquela época tínhamos disciplinas que não tinham em nenhum outro curso, por exemplo, nós tínhamos disciplinas de Informática Médica, as pessoas saiam qualificadas. Lembre-se que nós estamos falando de 1986, computador não tinha ainda disco rígido, era só disquete. O professor De Rose foi um visionário neste sentido, o LAPEX em 1976 já era todo informatizado, nós transferimos toda essa tecnologia para os médicos que vinham para cá e saiam qualificados. Nas Práticas Fundamentais de Informática, nós tínhamos uma disciplina de Estatística que também foi uma renovação ao que existia em Porto Alegre; as disciplinas de Estatística que eram oferecidas em todas as faculdades só ensinavam a dizer que a estatística existia, as pessoas não se qualificavam, os nossos médicos saiam trabalhando com programa de estatística e fazendo a sua própria análise estatística. Mas acho que isso foi um momento de brilho também para o LAPEX, no sentido de que trouxe tecnologia internacional em um curso de pósgraduação, no caso aqui Lato Senso de Medicina do Esporte, aproveitando uma 
grande dedicação que esses médicos que vinham do exterior tinham. Eu acho que foi um momento importante. E nessa época nós conseguimos produzir vários trabalhos internacionais também. Agora já estamos nos aproximando dos anos 1990 quando começou o curso de pós-graduação Strictu Sensu, eu não me lembro bem, vocês chequem depois a data, eu acredito que tenha sido início dos anos 1990.

C.M. -1989 ?

J.R. - Isso 1989. Foi um início complexo, como são todas as coisas na ESEF, ao contrário de uma Faculdade de Medicina que eu conheço profundamente, onde só existe uma linguagem, se chama linguagem biológica, aqui só tem uma língua, Faculdade de Medicina, só tem linguagem biológica. A Educação Física é multidisciplinar e as técnicas de pesquisa, as técnicas de ensino de aprendizagem são distintas. E esse é um conflito que existe há muitos anos dentro da ESEF, existe agora, naquela época era pior e havia muita disputa entre essas áreas, uma falta de entendimento. Acho que hoje as pessoas que lideram são capazes de entender a multidisciplinaridade e se respeitar, mas isso continua sendo um desafio para a Educação Física. [...] Ao longo desses tempos, nós já estamos em 1989 a partir do final dos anos de 1980 teve início dos anos de 1990, a minha vida acadêmica aqui na Faculdade de Medicina... Eu entrei como professor concursado aqui também, começou a demandar muito, e ficou difícil para eu cumprir as minhas atribuições na ESEF porque o tempo começou a ficar curto. Eu fui diretor do LAPEX de 1986 a 1992, [...] eu fazia pesquisa e dava aula na pós-graduação, então, eu tinha atividades relativamente amplas. Além disso, eu estava aqui e tinha também uma atividade privada como cardiologista; além disso eu tinha mais uns cinco cargos diretivos incluindo naquela época eu era Diretor da área de Saúde da Fundação de Amparo à Pesquisa do Estado do Rio Grande do Sul, que também tomava tempo. [...] Eu, na realidade, fui nomeado até por ter esta dupla atividade na Medicina e na Educação Física, eu transitava melhor pela área da Saúde, e isso era valorizado. E com todas essas responsabilidades ficou evidente em 1992 que eu tinha que fazer uma opção, e a opção que eu fiz foi me demitir da ESEF e ficar só na Faculdade de Medicina; então eu pedi demissão, acho que foi uma opção adequada porque a minha vocação maior era para trabalhar aqui, mas eu não estava dando conta, eu não me sentia bem e não cumpri com todas as responsabilidades que eu tinha frente a ESEF embora eu sempre tenha cumprido com tudo que era esperado no sentido de carga horária, responsabilidades didáticas e produção científica, mas não era suficiente para mim. Pedi demissão da ESEF e fiquei lotado só na Faculdade de Medicina. E a partir de 1992 eu continuei ligado por vários anos, e agora não saberia dizer, por quantos anos mais.
Recebido 28/01/2013 Aprovado 05/02/2013 